\section{Sobre a intolerância: percursos semióticos}

On intolerance: semiotic paths

Alexandre Marcelo BUENO (UPM) alexandrembueno@gmail.com

Recebido em: 17 de dez. de 2019. Aceito em: 05 de fev. de 2019.
BUENO, Alexandre Marcelo. Sobre a intolerância: percursos semióticos. Entrepalavras, Fortaleza, v. 10, n. esp., p. 40-56, mai. 2020. DOI: 10.22168/2237-6321-7esp1796

Resumo: Como fenômeno da significação, a intolerância continua fortemente presente na contemporaneidade. O objetivo deste trabalho é o de examinar o discurso intolerante a partir das propostas desenvolvidas pela semioticista Diana Luz Pessoa de Barros a partir do quadro teórico da semiótica discursiva de linha francesa, desenvolvida por Algirdas Julien Greimas. Por meio de diversos exemplos, veremos as características que denotam esse tipo de discurso, assim como analisaremos casos concretos do uso da intolerância no campo político, tal como propõe a semioticista brasileira. Por fim, mostraremos como esta pesquisa revela, além de sua importância atual para combater tal fenômeno, um estilo de pesquisa, ou seja, um ritmo e uma maneira de refletir sobre a significação em geral.

Palavras-chave: Intolerância. Semiótica discursiva. Discurso político. 
Abstract: As a phenomenon of meaning, intolerance remains strongly present in contemporary society. The objective of this work is to examine the intolerant discourse from the proposals developed by the semioticist Diana Luz Pessoa de Barros from the theoretical framework of the French line discursive semiotics, developed by Algirdas Julien Greimas. Through various examples, we will see the characteristics that denote this type of discourse, as well as analyze concrete cases of the use of intolerance in the political field, as proposed by the Brazilian semioticist. Finally, we will show how this research reveals, in addition to its current importance in combating this phenomenon, a style of research, that is, a rhythm and a way of reflecting on meaning in general.

Keywords: Intolerance. Discursive semiotics. Political discourse.

\section{Considerações iniciais}

A intolerância está, infelizmente, na ordem do dia. Os acontecimentos políticos do país, ao menos desde 2014, após a eleição de Dilma Rousseff em um segundo turno apertado contra Aécio Neves, produziu uma escalada nos discursos de ódio contra a esquerda e os grupos sociais minoritários. Este trabalho, elaborado como forma de homenagear a Profa. Dra. Diana Luz Pessoa de Barros, se constitui por dois percursos distintos. O primeiro pretende recuperar as características do discurso intolerante a partir do percurso de pensamento que a homenageada estabeleceu desde o início de suas reflexões acerca do fenômeno da intolerância e do preconceito por meio do uso dos conceitos e métodos de análise da semiótica, em que se observa um refinamento contínuo que a semioticista brasileira foi realizando nos diversos trabalhos sobre o assunto. Em segundo lugar, retomar o percurso histórico recente do discurso intolerante na sociedade brasileira, com destaque ao atual presidente da república. Desse modo, esperarmos mostrar como a semiótica, por um lado, desenvolve a análise do discurso intolerante e, por outro, assim render as devidas homenagens a quem melhor refletiu entre nós sobre o assunto, sem deixar de se posicionar de modo didático e democrático, elementos que se têm se tornado lamentavelmente raros na vida social do país.

Não trataremos aqui do que fizemos em relação ao discurso intolerante, a não ser por meio de alguns exemplos retirados de trabalhos já realizados, nem recorreremos ao pensamento de intelectuais e pesquisadores que já trataram do fenômeno da intolerância em outros campos, como a Filosofia, a Sociologia ou a Antropologia e que nos auxiliaram a pensar na organização do discurso intolerante em trabalhos anteriores (BUENO, 2015). Escolhemos esse caminho porque, primeiramente, gostaríamos de privilegiar as conquistas teóricas e 
10 (esp.)

40-56

mai.

2020

analíticas obtidas pelo trabalho desenvolvido por Barros (tanto pelas suas ideias originais como pelo diálogo que estabelece com o que outros semioticistas elaboraram); em segundo lugar, para mostrar o alcance da semiótica como teoria que dá conta de reunir várias das questões ligadas à intolerância que aparecem frequentemente difusas em diferentes perspectivas teóricas.

Este artigo está dividido em duas partes: a primeira se refere à organização do discurso intolerante, caracterizado pela sanção e, principalmente, pela punição; pelas paixões do medo e do ódio; pela construção das isotopias temáticas e figurativas que revelam a disposição ideológica inconsciente; e pela tensividade, enquanto uma maneira de compreender o caráter excepcional da intolerância na dinâmica social. A segunda parte do texto se refere ao papel do discurso intolerante do campo político brasileiro.

No entanto, antes de partir para o detalhamento de cada um dos componentes do discurso intolerante, devemos fazer alguns esclarecimentos mais gerais. Primeiramente, é preciso mencionar que discurso intolerante não se constitui em nem é veiculado por somente um único gênero discursivo ou um tipo textual (BARROS, 2008). Pelo contrário, os discursos intolerantes se manifestam por meio de diferentes gêneros e a única forma de reconhecê-los é por meio da unidade temática em sua composição, que será então detalhada ao longo de nossa análise.

Além disso, fazer uma diferenciação entre uma intolerância primária e uma intolerância secundária é necessária porque percebemos que há intolerâncias que são mais condenadas ou criticadas do que outras na dinâmica social. É o racismo e a homofobia para o primeiro caso e a intolerância linguística para o segundo. Desse modo, não é incomum se recorrer à intolerância linguística para camuflar ou atenuar uma intolerância primária. É o caso, por exemplo, de se criticar a fala dos jovens que gostam de funk, o uso de determinadas gírias, enquanto o desejo era o de discriminar o outro por sua origem social, sua cor da pele, sua identidade de gênero, entre outros (BARROS, 2008).

Essa diferenciação entre uma intolerância primária e uma intolerância secundária nos indica também como a linguagem é utilizada para a diferenciação entre uma intolerância na linguagem e uma intolerância da linguagem. A intolerância na linguagem é aquela que constrói a imagem negativa do outro, da alteridade, do diferente. É a intolerância contra negros, mulheres, populações originárias, população 
LGBTTI+, imigrantes e refugiados. Em resumo, é a intolerância que destaca o que se considera negativo no outro e mobiliza temas como o racismo, a homofobia, o machismo, a xenofobia entre outros. Já a intolerância da linguagem se refere à intolerância contra a língua do outro: do estrangeiro (a depender, sempre, da origem desse estrangeiro), do modo como este estrangeiro fala a língua de um país que não é o seu, e esta é também a intolerância contra as variantes linguísticas desprestigiadas, dos pouco escolarizados, mas também dos portadores de determinados sotaques, como o caipira em São Paulo (BARROS, 2008).

Como já mencionamos, a intolerância da linguagem pode servir para camuflar ou atenuar uma intolerância latente mais grave do ponto de vista social em relação a minorias. Por isso, a intolerância da linguagem pode ser usada como uma estratégia para se criticar minorias, pois assim não se corre o risco de ser acusado de ser racista, homofóbico, entre outros qualificativos possíveis do sujeito intolerante (BARROS, 2008). Feitas essas observações iniciais, passemos para a primeira questão da intolerância: a organização narrativa e discursiva da intolerância.

\section{A organização narrativa e discursiva da intolerância}

A primeira característica do discurso intolerante é a de que ele se configura como um discurso de sanção em que os sujeitos vítimas da intolerância são considerados maus cumpridores de certos contratos sociais, que visam, a depender do momento histórico do Brasil, o branqueamento da sociedade, a pureza da língua, a heteronormatividade. Assim, por não poderem cumprir com esses contratos sociais, esses sujeitos seriam considerados maus cidadãos que deveriam ser punidos com a perda de direitos sociais, com a perda de empregos e, em casos mais graves, até mesmo com a perda da vida (BARROS, 2011).

Para tratar do caso dessa forma de sanção, apresentamos abaixo o exemplo de uma professora da Faculdade de Direito da USP. Neste trecho, ela mostra claramente que sua sanção é contrária à presença de imigrantes bolivianos no país pelo simples fato de que, em sua perspectiva, eles não contribuem em nada para o desenvolvimento econômico, social e cultural do país. Por essa razão, nem se deveria estar discutindo questões políticas das relações Brasil-Bolívia: 


\section{v. 10 (esp.}

40-56

mai.

2020

Isso é insignificante para nós. A Bolívia é insignificante em todas as perspectivas. É um país, sim, que tem uma fronteira enorme com o Brasil. Dos nossos vizinhos, é o que tem maior fronteira terrestre, mas nós não temos nenhuma relação estratégica com a Bolívia. Nós não temos nenhum interesse comercial com a Bolívia. Os brasileiros não querem ir pra Bolívia. Os bolivianos que vêm de lá tentando uma vida melhor aqui não contribuem para o desenvolvimento tecnológico, cultural e social e desenvolvimentista [sic] do Brasil. Então Bolívia é um assunto menor (... $)^{1}$.

Além disso, essas sanções podem ter implicações para as interações entre os sujeitos. Uma sanção negativa pode, por exemplo, levar a uma segregação ou a uma exclusão efetiva, talvez a forma mais explícita de intolerância. Ser um mau imigrante, porque não contribui para o desenvolvimento cultural, econômico e social do país que o acolhe pode ser justificativa para a perseguição e expulsão desses sujeitos.

No entanto, uma sanção negativa pode também levar a um processo de assimilação do outro que, como Landowski (2002) nos mostra, é uma operação em que a alteridade deve abrir mão daquilo que a caracteriza justamente como alteridade. No caso da intolerância, um sujeito é obrigado a se comportar de determinada maneira, apresentar um certo tom de voz, uma certa postura, um comportamento adequado etc. para cumprir um contrato social sobre a sexualidade, em outras palavras, para se passar, por exemplo, como homem. Quando Bolsonaro menciona a frase abaixo, é sobre assimilação que ele está tratando, pois não se pode admitir, segundo seu ponto de vista machista e homofóbico, que um sujeito, na posição de seu filho, não cumpra o contrato social de ser homem: "Se o filho começa a ficar assim, meio gayzinho, [ele] leva um couro e muda o comportamento dele" (FOLHA, 2010).

Em relação aos percursos passionais do discurso intolerante, Barros (2015) observa o predomínio das paixões do ódio e do medo, enquanto efeitos de sentido organizados por meio de modalidades compatíveis e incompatíveis em sua sintaxe modal. Para tratar da paixão do medo, retomamos muito rapidamente o estudo de Fiorin (1992) que afirma haver dois tipos de medo: o dissuasório, que é entendido como um sujeito que age segundo determinada norma social, ou seja, possui o medo de uma sanção pragmática negativa do destinador. E medo do outro que ocorre sobretudo em situação de desigualdade social, por medo de se perder algo ou ser espoliado por um antissujeito, pois está

1 Transcrição realizada pelo autor. Disponível em: https://www.youtube.com/ watch?v=WldDhotNwFg 
disputando o objeto de valor com o sujeito em questão. É geralmente este segundo, o medo do outro, que caracteriza o discurso intolerante, porque serve para justificar a ação intolerante.

A paixão do medo pode fazer crescer a intensidade dos percursos passionais e das ações intolerantes, sobretudo em momentos de crise. $\mathrm{O}$ medo se refere a uma possível perda de seu objeto de valor e tem essa expectativa porque cria determinados simulacros da alteridade. Assim, é a perda de trabalho por causa dos imigrantes, é o medo de se perder a propriedade privada para os comunistas, o medo de se perder privilégios para que as minorias tenham acesso a direitos básicos e o medo de se perder a própria sexualidade ou a constituição da família tradicional brasileira, alguns dos temas frequentes nesse tipo de discurso. É o que observamos, por exemplo, no trecho abaixo, da ministra do atual governo:

\begin{abstract}
"Eu posso fazer nas escolas um grande trabalho de combate ao preconceito sem agredir a identidade biológica das nossas crianças e sem destruir a imagem da família. Mas isso não está acontecendo no Brasil. Aqui está havendo uma verdadeira guerra contra a família", disse a doutora (CHAGAS, 2015).
\end{abstract}

Além da paixão do medo, Barros (2015) também menciona paixões malevolentes como parte do discurso intolerante. Assim, paixões como o ódio, a antipatia, a raiva, a xenofobia são paixões do querer fazer mal a um sujeito que não cumpriu sua parte do contrato social. A paixão malevolente geralmente é acompanhada de uma paixão benevolente presente no mesmo sujeito intolerante, mas direcionada aos seus iguais, como o amor à pátria, aos de sua cor, de sua religião etc. Essa etapa das paixões malevolentes é ainda o que podemos chamar de preconceito. A intolerância propriamente dita é aquela em que se parte justamente para fazer mal ao outro nos percursos de revolta e vingança (BARROS, 2015).

Barros, assim, retoma o clássico estudo sobre a cólera de Greimas (2014). Resumidamente, Greimas afirma que um sujeito parte de um estado inicial de satisfação, etapa em que acredita que receberá a devida recompensa por meio de um outro sujeito. Quando esse sujeito satisfeito percebe que não receberá a recompensa esperada, ele passa a um estado de insatisfação prolongada, em que se instauram as paixões da decepção e da frustração, podendo chegar até mesmo ao desespero e à insegurança em relação a si mesmo. Logo, esse sujeito elabora e parte para uma ação malevolente em que ele vai tentar reestabelecer o equilíbrio passional em uma situação que ele considera uma injustiça. 
10 (esp.)

40-56

mai.

2020

A fase da intolerância é aquela em que o sujeito preconceituoso, ou seja, decepcionado, frustrado ou desesperado e já portador da paixão do ódio, passa para o que Greimas chama de percurso da vingança ou da revolta. Assim chegamos à fase de moralização social, o que aparece como aceitação ou recusa das paixões sociais, avaliadas como de prestígio ou desprestigiadas, como no caso da vingança. Na sociedade brasileira, em geral, a moralização sobre as paixões do medo e do ódio não são bem aceitas, a não ser em determinadas situações. Discursos, como o seguinte, contra a presidenta Dilma Rousseff parece ser um exemplo adequado para mostrar um tipo de paixão que foi sancionada positivamente por aqueles que se colocaram contra a primeira presidente mulher do país, um pouco antes de ela ser deposta em 2016:

"Espero que o mandato dela acabe hoje, infartada, com câncer ou de qualquer maneira", disse. "O Brasil não pode continuar sofrendo com uma incompetente, ou 'incompetenta', à frente de um país tão grande e maravilhoso como esse aqui" (AZEVEDO, 2015).

Assim, o ódio ao outro por ser tão diferente encontra lugar no mesmo sujeito que é também o que sente o amor à pátria, à sua língua, ao seu grupo social e político. Essa é uma das características do sujeito intolerante: querer fazer mal ao diferente ao mesmo tempo em que quer fazer bem aos seus semelhantes. Em outras palavras, ele divide o mundo entre o "nós e o eles", preenchendo essa distância com paixões malevolentes contra o diferente e benevolentes aos seus semelhantes.

Após observamos a organização narrativa e passional do discurso intolerante, passemos para o exame dos temas e figuras nos mesmos discursos. No nível discursivo, vamos ter de um lado os temas que são tratados como conteúdos abstratos que categorizam o mundo enquanto as figuras são a cobertura sensorial dos temas, é o que lhes dá concretude (BARROS, 2015). Tanto temas como figuras são determinados social e historicamente, pois são conceptualizações e representações de um ponto de vista em relação ao mundo a partir dos grupos e das classes sociais em um momento histórico dado, em um processo que podemos chamar de articulação ideológica dos discursos.

Segundo Barros, de um modo geral, discursos intolerantes tratam de temas e figuras relacionados a duas oposições fundamentais entre igualdade versus diferença ou identidade versus alteridade. Barros identifica quatro procedimentos recorrentes que elaboram os percursos temáticos e figurativos próprios dos discursos intolerantes: 
a animalização do outro; a antinaturalidade do diferente; o caráter doentio da diferença; a imoralidade do outro (BARROS, 2016a).

O primeiro percurso temático-figurativo atribui ao outro características físicas e comportamentais de animais. Essa é uma estratégia que serve para desumanizar o outro e lhe tirar traços semânticos que o definem como um ser humano. Essa organização é encontrada em discursos racistas ou mesmo em discursos relacionados à disputa política, como vemos a seguir: "Ele deveria comer capim ali fora para manter as suas origens (2008)" (FOLHA, 2018). Na mesma linha, vejamos a seguinte afirmação, também do atual presidente da república:

Fui num quilombola em Eldorado Paulista. Olha, o afrodescendente mais leve lá pesava sete arrobas. Não fazem nada! Eu acho que nem para procriadores servem mais. Mais de R\$ 1 bilhão por ano é gastado com eles (2017) (FOLHA, 2018)

Em ambos os casos, o discurso de Bolsonaro rebaixa o outro ao entrelaçar, semanticamente, o homem e traços de animais (peso, ato de comer etc.). Desse modo, ele promove um distanciamento daqueles que são diferentes dele e os coloca em uma posição inferior, como se fossem animais para o trabalho ou para reprodução da espécie.

O segundo tema elabora o outro como antinatural. Ele se caracteriza por difundir uma ideia de anormalidade, a partir de um suposto padrão social e cultural que é quase sempre universalizado pelo sujeito intolerante. Assim, o outro é estranho para o sujeito intolerante, enquanto os iguais são reconhecidos como normais e naturalizados. Haveria, nessa perspectiva, uma sexualidade considerada contrária a ordem natural das coisas, como no caso da homossexualidade, uma vez que a Bíblia diria o contrário do que é praticado por alguns sujeitos. É essa perspectiva que observamos no trecho a seguir:

Em apostilas disponibilizadas pelo professor em seu site pessoal, o educador classifica o que ele chama de "homossexualismo" como "anomalia sexual", na categoria "aberrações e perversões sexuais", junto com a zoofilia, a necrofilia, o sadismo e o vampirismo, alegando que essas "facilmente levam a (sic) morte por homicídio".

Em outro material, o "homossexualismo" aparece na lista de "aberrações ou desatinos sexuais", ao lado da pedofilia e do estupro. "Pederastas ou lésbicas poderão, em nome do amor, praticar tipos diferentes de crimes por motivações ciumentas", diz uma das apostilas disponibilizadas pelo professor Alírio Batista na internet. 


\section{10 (esp.)}

40-56

mai.

2020

De acordo com Diógenes, o material disponibilizado no site é utilizado em sala de aula e exigido nas provas das disciplinas. "Esse é o material indicado para estudo e, na prova, a gente tem que responder tudo que ele coloca no material", explicou (G1, 2017).

O terceiro tema se caracteriza pela ideia da diferença do outro como algo doente ou doentio. Há uma estética, inclusive, relacionada a esse tema, sobretudo por meio da questão da saúde, dos corpos sadios, que se contraporiam aos corpos obesos, disformes. Assim, há a busca do belo em relação à escapatória do feio, muitas vezes em decorrência de uma doença, por exemplo. Então, uma série de grupos sociais podem ser atacados em suas características físicas, como surdos, cegos, obesos, portadores de necessidades especiais, entre outras possibilidades, como vemos no seguinte fragmento:

[Michele] Maximino é reconhecida por ser a maior doadora de leite materno do país e já doou mais de 425 litros a bancos de leite do estado, mas a exibição de sua imagem sem autorização e as ofensas no programa fizeram com que ela passasse por vários transtornos.

"O apresentador Danilo Gentili começa a sua explanação relatando a constatação da existência de uma Pernambucana grande doadora de leite materno, pois a mesma já doara mais de 300 litros de leite, momento em que o apresentador Marcelo com um copo de leite na mão faz uma expressão de nojo, e, prossegue o apresentador Danilo falando que 'em termos de doação de leite ela está quase alcançando o Kid Bengala', tendo Marcelo perguntado: 'Qual o tamanho das tetas?' e em seguida é divulgada a imagem da autora com trajes adequados para a captação do leite, mostrando um decote com seios em parte à mostra", diz trecho da sentença publicado pela EBC.

"Prossegue Marcelo dizendo: 'gente isso não é uma espanhola é uma América Latina inteira', momento em que o cantor Roger explica que a Espanha fica na Europa e não na América Latina, tendo o apresentador Marcelo explicado que espanhola 'é quando você se masturba entre os orifícios dos seios', tendo o Danilo interrompido o colega e dito que no programa dele há um termo de cavalheiros para ser utilizado e revela que espanhola é 'bater masturbação' e mostra a foto da autora novamente, prosseguindo o Danilo afirmando que a autora é a parte de cima (cabeça) e plutão e saturno logo abaixo (seios). E continua o apresentador Danilo noticiando que 'depois que ela viu que não vai ganhar nada doando leite, ela resolveu vender' e aparece uma caixa de leite moça, intitulada "leite da moça" com a imagem da autora estampada na mesma", continua o texto.

Ela contou ao G1 que teve que se mudar da cidade de Quipapá por causa da exibição do material da Band, já que virou alvo de chacota dos moradoras, além de ter problemas com o sono e passar por estresse (CATRACA LIVRE, 2017). 
Trata-se, neste caso, de acentuar um traço físico de uma mulher (o tamanho de seus seios e sua capacidade de amamentação, que ela utiliza para fazer o bem) e, ao mesmo tempo, cruzar essa característica com a animalização do outro, sobre a qual já tratamos.

A quarta composição trata do tema sobre a moralidade e uma suposta falta de ética na alteridade, que se refere também a certos comportamentos sociais que são considerados promíscuos, vergonhosos e socialmente inadequados. Em suma, a intolerância surge quando a diferença que caracteriza o outro é sempre referente a um distanciamento de um padrão social normativo e hegemônico construído para assentar uma visão de mundo desse sujeito intolerante. É essa perspectiva que observamos no trecho abaixo, um fato que envolveu o atual presidente da república:

Ô. Preta [Gil], eu não vou discutir promiscuidade com quem quer que seja. Não corro esse risco porque meus filhos foram muito bem educados e não viveram em ambientes como lamentavelmente é o teu (2011) (FOLHA, 2018)

Vemos assim que, ao julgar o outro, o intolerante revela também o seu conjunto de valores morais. Nesse caso, a pergunta se referia ao modo como o atual presidente da república se comportaria caso um filho seu se relacionasse com uma mulher negra. Apesar de ter alegado não ter escutado bem a pergunta, o que importa é que quem profere o enunciado mostra ter valores diferentes de quem fez a pergunta e, por isso, julga que os seus valores são melhores que os do outro porque o ambiente familiar seria supostamente melhor, aparentemente correto.

Para fechar esta seção, trataremos da incorporação das propostas da semiótica tensiva, elaborada sobretudo por Zilberberg (2011), realizada por Barros (2016a; 2016b) para abrir novas possibilidades de entendimento deste fenômeno. A primeira característica do discurso intolerante, nessa perspectiva teórica, é que ele é da ordem do acontecimento, pois ele imprime uma marca fortemente passional sobre o sujeito e, após o impacto, uma reação ao inesperado. Contudo, Barros também afirma que, mesmo com essas caraterísticas, o discurso intolerante pode adquirir traços de racionalidade e de inteligibilidade, características ligadas ao exercício, principalmente quando busca apresentar uma justificativa para fundamentar sua intolerância. Assim, discursos da ordem do exercício são aqueles como, por exemplo, o discurso da ciência no século XIX, em que havia o predomínio de um darwinismo social que esteve em evidência no Brasil, em que havia uma 


\section{v. 10 (esp.}

40-56 mai. 2020

hierarquização das raças, com a raça branca tomada como superior, enquanto a amarela era vista como intermediária e, por fim, a raça negra como inferior.

Barros (2016a) utiliza ainda os conceitos de triagem e mistura, assim como os conceitos de contiguidade, mescla e fusão envolvidos no processo de mestiçagem proposto por Zilberberg e, no mesmo artigo, os conceitos de triagem, que são os de exibição, extração e separação.

Artigo $1^{\mathrm{O}}$. - É inteiramente livre a entrada, nos portos da República, dos indivíduos válidos e aptos para o trabalho, que não se acharem sujeitos à ação criminal do seu país, excetuados os indígenas da Ásia, ou da África que somente mediante autorização do Congresso Nacional poderão ser admitidos de acordo com as condições que forem então estipuladas (Iotti, 2001, p. 452). .

O que observamos nesse trecho é o processo de separação, enquanto uma triagem plena e acabada, de uma disjunção tônica. Podemos ainda chamar, em um outro nível do percurso gerativo do sentido, de exclusão nos termos de Landowski (2002). Ao mesmo tempo, há uma mistura prevista, referente aos "indivíduos válidos e aptos para o trabalho", que nada mais são do que os brancos europeus. Aí incide uma triagem por extração de uma totalidade quase amorfa, pois pouco distinta a partir do sema imigração.

O uso de um tipo de discurso ou outro depende da época em que ele surge, dos grupos sociais e das estratégias discursivas utilizadas na relação entre enunciador e enunciatário. O mencionado discurso científico darwiniano do século XIX não encontra mais lugar de destaque nos debates dos movimentos identitários contemporâneos, mas ainda sustenta grupos conservadores e reacionários, como os neonazistas e os supremacistas brancos.

Além das características que apresentamos, baseados nos estudos de Barros, a intolerância também deve ser discutida na dinâmica social em que ela se manifesta. Por essa razão, entendemos que há necessidade de inserir a semiótica em alguns dos debates atuais, seja no campo político partidário propriamente dito, seja em temas associados à política em sentido mais amplo, como é o caso em que Barros vai desenvolver considerações a respeito do direito à liberdade de expressão, em especial a liberdade de pensamento e expressão dos preconceitos, um tema bastante atual. Passemos, então, para a segunda parte de nosso texto. 


\section{O uso da intolerância nos discursos políticos}

Barros parte da ideia de que o discurso político é o discurso do poder, ou seja, de um sujeito modalizado pelo poder e da busca pelo poder como valor, além das narrativas de seu reconhecimento e de sua conservação por um determinado grupo social. O discurso político pode envolver também diferentes papéis temáticos circunscritos a esse universo, como os candidatos aos cargos eletivos, deputado, vereador, presidente, senador etc. Além disso, o discurso político é marcado pelo seu caráter manipulatório, pois visa ao convencimento de um eventual eleitorado. Por isso, o sujeito político candidato precisa se mostrar confiável e como um sujeito do saber (e não apenas do poder) (BARROS, 2013).

Podemos observar na atualidade como a religião começa a fazer parte da dinâmica de elaboração de discursos intolerantes. Esse é o caso do discurso de Marcos Feliciano, assim como de outros pastores políticos ou políticos pastores que tratam de defender a suposta liberdade de expressão para permitir comentários homofóbicos ou racistas no espaço dos templos e igrejas em que supostamente professam sua fé. Como vemos na Figura 1 a seguir, tirado de uma postagem na página do referido sujeito, ele estabelece como prioridade a liberdade religiosa em detrimento da igualdade de relações que não permite a ofensa, a discriminação ou qualquer outra forma de segregação ou exclusão, elementos presentes em discursos homofóbicos e racistas. 
v. 10 (esp.) 40-56 mai. 2020
Figura 1 - Impressão de postagem do pastor e deputado Marco Feliciano

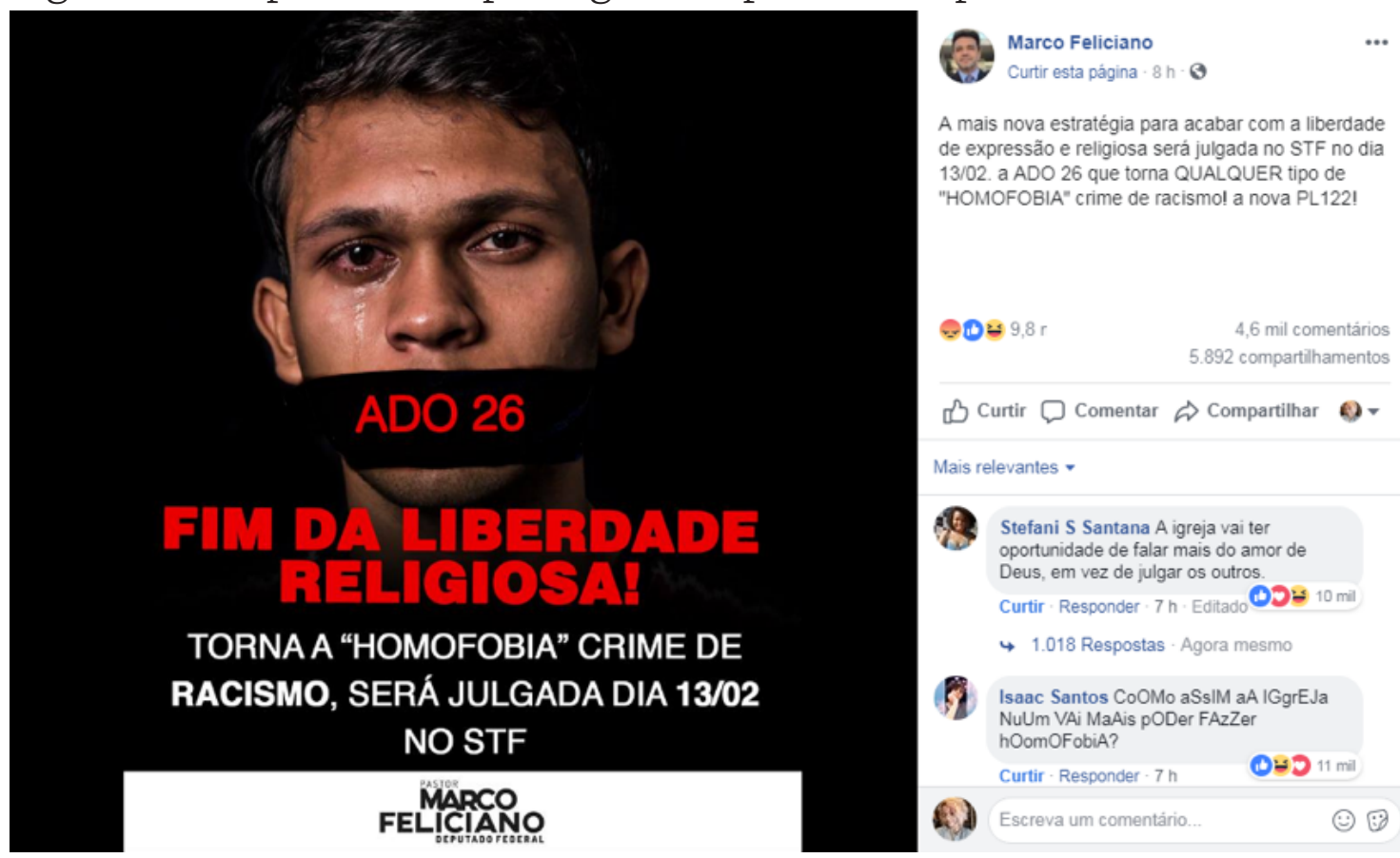

Fonte: Facebook. Disponível em: < https://www.facebook.com/PastorMarcoFeliciano/ photos/a-mais-nova-estrat\%C3\%Aggia-para-acabar-com-a-liberdade-deexpress \%C3\%A30-e-religiosa-ser\%C3\%A1/1481541701985844/>. Acesso em: 06 maio 2019.

A Ação Direita de Inconstitucionalidade por Omissão 26 (ADO 26) foi julgada pelo Supremo Tribunal Federal (STF), adequou a homofobia e a transfobia ao crime de racismo (e, em especial, de racismo social). Desse modo, sujeitos que incorrerem neste crime passam a cumprir as mesmas penas da lei de racismo original. O que a postagem de Marco Feliciano faz é questionar a ADO 26, relativizar a homofobia existente nas igrejas (pois a homossexualidade é um pecado capital para essas religiões) e ainda acusa o STF de estabelecer o fim da liberdade religiosa, como se os intolerantes fossem, nesse caso, o próprio tribunal e seus membros. Desse modo, é como se ele afirmasse que os intolerantes (do STF) não estão permitindo que ele exerça sua liberdade de dizer o que a bíblia afirma ser o correto. Contudo, essa postura pode ser lida por um outro viés: trata-se da imposição de limites do STF para que a intolerância não encontre respaldo em espaços religiosos, como parece desejar o referido pastor-político.

Como dissemos anteriormente, o discurso político é a construção da credibilidade do sujeito. Para alcançar esse efeito de sentido junto ao eleitorado e ao seu grupo social, o sujeito intolerante não se apresenta somente como um destinador-manipulador, mas também 
como um sujeito manipulado, cuja modalidade que lhe é atribuída é da ordem do saber. Assim, ele se apresenta como manipulado pelos valores da nação, pelos valores da opinião pública, pela voz do povo, como ele procura mostrar no trecho a seguir:

- "Deus acima de tudo. Não tem essa historinha de Estado laico não. O Estado é cristão e a minoria que for contra, que se mude. As minorias têm que se curvar para as maiorias" (encontro na Paraíba, fevereiro de 2017) (FOLHA, 2018).

Trata-se de uma clara tentativa de se construir uma suposta credibilidade que justificaria todos os desejos e todas as ações que ele porventura venha a realizar. Desse modo, ele se coloca autorizado por uma instância superior a fazer o que bem entender, uma vez que ele foi devidamente manipulado para cumprir a missão de conduzir o país.

Outra possibilidade de construção da credibilidade é por meio da constituição de um éthos de sujeito autêntico, ou seja, daquele que fala o que pensa, sem se importar com moralizações ou julgamento de outros. É quando o ator do discurso se mostra como manipulador de si mesmo:

Seria incapaz de amar um filho homossexual. Não vou dar uma de hipócrita aqui. Prefiro que um filho meu morra num acidente do que apareça com um bigodudo por aí (2011) (FOLHA, 2018).

Assim, o sujeito intolerante, uma vez que ele se coloca como o representante escolhido, pode afirmar que age de maneira preconceituosa e intolerante porque está a mando de um manipulador específico (o país, o povo, deus), o que lhe permite gerar um efeito de identificação entre parcela do seu eleitorado que compartilha dos mesmos valores.

Esta estratégia discursiva, presente em alguns discursos intolerantes, justifica a postura e os valores do sujeito intolerante por ser supostamente intolerante ao intolerável (vindo do outro, da alteridade). Assim, essa estratégia justificaria a intolerância de uma autoridade política na medida em que a alteridade comportaria características e valores, que o próprio sujeito intolerante constrói sobre ela, de ameaça, de inferioridade, de práticas sociais condenáveis, como a promiscuidade, entre outras possibilidades. É o que podemos observar, por exemplo, no trecho seguinte, em mais uma lamentável fala do atual presidente da república:

"Não sei qual é a adesão dos comandantes, mas, caso venham reduzir o efetivo [das Forças Armadas] é menos gente nas 
10 (esp.)

40-56

mai.

2020 ruas para fazer frente aos marginais do MST, dos haitianos, senegaleses, bolivianos e tudo que é escória do mundo que, agora, está chegando os sírios também. A escória do mundo está chegando ao Brasil como se nós não tivéssemos problema demais para resolver" (AZEVEDO, 2015).

A frase acima possui a mesma estrutura do enunciado em que Bolsonaro diz que a Preta Gil teria um comportamento intolerável, segundo seu padrão "moral". Assim, ao sancionar os refugiados como "escória do mundo", observamos que Bolsonaro joga para o "seu público", mostrando que os refugiados não são dignos para entrar e permanecer no país. Fica implícita também a necessidade, do ponto de vista do enunciador, de promover uma triagem por separação para não ameaçar a composição da grandeza chamada Brasil. Por isso, deve-se excluir esses imigrantes, uma vez que moralmente eles não são capazes de cumprir com os contratos sociais para permanecer no país.

O sujeito político usa o seu lugar de sujeito do poder e do saber para fazer circular a intolerância como uma estratégia na qual se estabelece um limite entre o nós e o eles, a construção de um efeito de verdade e de certeza em seu discurso, além de poder se colocar como herói ou salvador da pátria, o ungido por deus, o guardião da moral e dos bons costumes. Em suma, o representante do povo, que o apoia, como fica evidente neste enunciado: "Pau-de-arara funciona. Sou favorável à tortura, tu sabe disso. E o povo é favorável também (1999)" (FOLHA, 2018).

O discurso político intolerante contribui para o crescimento do preconceito da intolerância como nós podemos observar, enfim, quase diariamente com o governo atual. Vivemos hoje, ousamos dizer, um momento de vingança dos sujeitos intolerantes que ficaram calados durante muito tempo por uma série de normas jurídicas e de coerções sociais que os impediam de manifestar seus preconceitos contra as diferentes formas de vida existentes em qualquer sociedade e cuja diversidade contraria os valores de unidade concentrados e se coloca contra a triagem que os intolerantes desejariam ver aplicada. Além do mais, Barros afirma que o mais grave de tudo é que o discurso do sujeito político intolerante pode não ser efetivamente intolerante, mas pode fazer os outros agirem de maneira intolerante e preconceituosa, como é o que vemos nas redes sociais, por exemplo, implicando então uma "desresponsabilização" de atos que flertam no mínimo com ações e legais criminosas, e que podem levar a uma maior desestabilização da democracia já tão precária que possuímos. 


\section{Considerações finais}

Como acontece em boa parte das conclusões de seus estudos sobre a intolerância, Barros diz que devemos pensar em contrapor tais discursos intolerantes com a elaboração de discursos tolerantes que comportem temas e figuras adequados a essa oposição, valorizando então contratos de diversidade, de mistura, de mestiçagem, de diálogo com a diferença, com a aceitação do outro, de solidariedade. Desse modo, a semioticista nos mostra como articular, de modo refinado e elegante, o arcabouço teórico da semiótica para um tema que se tornou tão urgente na atualidade, pela força dos acontecimentos diários, que é o discurso intolerante e também nos mostra caminhos para o diálogo com a dimensão social e política que uma pesquisa em semiótica pode tomar.

Gostaríamos ainda de acrescentar algo a essa proposta para a resistência e o combate à intolerância. Além da tolerância propriamente dita, acreditamos ser necessário pensar também na celebração como forma de combate à intolerância. Celebração que é uma espécie de homenagem mais intensa e que envolve também uma sanção eufórica em relação ao homenageado. Por isso, acreditamos que uma oportunidade como esta, que é mais do que homenagear a Profa. Dra. Diana Luz Pessoa de Barros, é sempre bem-vinda, pois devemos sempre celebrar a semiótica, nossos mestres e a própria vida. Porque, no fundo, é isso o que os intolerantes temem e odeiam: a força da vida.

\section{Referências}

AZEVEDO, R. Bolsonaro chama refugiados de "escória do mundo". Revista Exame, 22 set. 2015. Disponível em: <https://exame.abril.com.br/brasil/ bolsonaro-chama-refugiados-de-escoria-do-mundo>. Acesso em: 04 mai. 2019.

BARROS, D. L. P. de. 'Todos tenemos prejuicios, pero no todos discriminamos'. Reflexões sobre o discurso intolerante. In: BARROS, D. L. P. de. (Org.). Margens, periferias, fronteiras: estudos linguístico-discursivos das diversidades e intolerâncias. São Paulo: Editora Mackenzie, 2016a.

BARROS, D. L. P. de. Estudos discursivos da intolerância: o ator da enunciação excessivo. Cadernos de Estudos Linguísticos (UNICAMP), v. 58, p. 7-24, $2016 b$.

BARROS, D. L. P. de. Intolerância, preconceito e exclusão. In:. LARA, G. P.; LIMBERTI, R. P. (Org.). no livro Discurso e (des)igualdade social. São Paulo: Editora Contexto, 2015. 
10 (esp.)

40-56

mai.

2020

BARROS, D. L. P. de. Política e intolerância. In: FULANETI, O. N.; BUENO, A. M. (Orgs.). Linguagem e política. Princípios teórico-discursivos. $1^{\mathrm{a}} \mathrm{ed}$.São Paulo: Contexto, 2013.

BARROS, D. L. P. de. A construção discursiva dos discursos intolerantes. In: BARROS, D. L. P. de. (Org.). Preconceito e intolerância. Reflexões linguísticodiscursivas. São Paulo: Editora Mackenzie, 2011.

BARROS, D. L. P. de. Preconceito e intolerância em gramática do português. In: BARROS, D. L. P. de.; FIORIN, J. L. (Org.). A fabricação dos sentidos estudos em homenagem a Izidoro Blisktein. São Paulo: Humanitas, 2008.

BUENo, A. M. Para uma gramática da intolerância. Entremeios, v. 10, p. 5768,2015

CHAGAS, T. Escolas têm sido usadas para estimular a homossexualidade, diz doutora Damares Alves. Gospel+, 29 jan. 2015. Disponível em: $<$ https://noticias.gospelmais.com.br/escolas-sido-usadas-estimularhomossexualidade-74116.html $>$. Acesso em: 06 mai. 2019.

DANILO Gentili é beneficiado após ofensas a doadora de leite. Catraca Livre, 2017. Disponível em: <https://catracalivre.com.br/cidadania/danilo-gentilie-beneficiado-apos-ofensas-doadora-de-leite/>. Acesso em: 06 mai. 2019.

FIORIN, J. L. Algumas considerações sobre o medo e a vergonha. Cruzeiro Semiótico, Porto, v. 16, p. 55-63, 1992.

FOLHA de S. Paulo. Veja 11 frases polêmicas de Bolsonaro. Folha de S. Paulo, 2018. Disponível em: < https://www1.folha.uol.com.br/ poder/2018/10/veja-11-frases-polemicas-de-bolsonaro.shtml>. Acesso em: 06 mai. 2019.

GREIMAS, A. J. Sobre o sentido II. São Paulo: EDUSP/Nanquim, 2014.

IOTTI, L. H. Imigração e Colonização - Legislação de 1747-1915. Porto Alegre/ Caxias do Sul: Assembleia Legislativa do Estado do RS/EDUCS, 2001.

LANDOWSKI, E. Presenças do outro. São Paulo: Perspectiva, 2002.

PALMADA muda filho "gayzinho", declara deputado federal. Folha de S. Paulo, São Paulo, 26 nov. 2010. Disponível em: <https://www1.folha.uol.com.br/fsp/ cotidian/ff2611201025.htm>. Acesso em: 04 mai. 2019.

PROFESSOR trata 'homossexualismo' como 'aberração' em sala de aula, diz estudante. G1 Paraíba, 29 jun. 2017. Disponível em: <https:// g1.globo.com/pb/paraiba/noticia/professor-trata-homossexualismocomo-aberracá-em-sala-de-aula-diz-estudante.ghtml>. Acesso em: 04 mai. 2019.

ZILBERBERG, C. Elementos de semiótica tensiva. São Paulo: Atelier Editorial, 2011. 